\title{
Intraoperative graft patency validation: Friend or foe?
}

Rami Akhrass, MD, and Faisal G. Bakaeen, MD
It is estimated that $3 \%$ to $5 \%$ of internal thoracic artery (ITA) and $20 \%$ of saphenous vein grafts (SVGs) fail at 1 year, frequently attributed to technical issues. ${ }^{1}$ The PREVENT IV (Project of Ex-vivo Vein Graft Engineering via Transfection) trial reported a $30 \%$ vein graft failure rate at 1 year, most without a major adverse cardiac event. ${ }^{2}$

Coronary artery bypass grafting (CABG) in the United States is typically performed on cardiopulmonary bypass (CPB), which provides surgeons with good visualization in a bloodless and motionless field, allowing them to "perfect" their work! In addition, greater than $85 \%$ of all grafts in the United States use SVGs as conduits that are forgiving and easy-to-use. ${ }^{3}$ Once the distal anastomosis is completed, selective perfusion of the vein graft provides flow measurements and solid information of a successful anastomosis.

The improved graft patency and clinical outcomes with arterial conduits compared with veins have increased calls for multiarterial grafting (MAG) and to maximize myocardial supply by ITA grafts. ${ }^{3-7}$ However, arteries are more delicate and susceptible to injuries, such as dissections and hematomas, that may compromise flow. In addition, arteries are "dynamic" structures with flow substantially influenced by a myriad of factors, such as spasm, hemodynamic parameters, and target-vessel specifications (especially the severity of stenosis), making routine intraoperative flow verification prudent.

From a quality assurance perspective, validation of intraoperative graft patency provides the opportunity, if needed, to correct any technical issues before leaving the operating room. Since intraoperative completion angiography is

\footnotetext{
From the Center for Coronary Revascularization, Department of Thoracic and Cardiovascular Surgery, Coronary Revascularization Center, Heart, Vascular and Thoracic Institute, Cleveland Clinic, Cleveland, Ohio.

Received for publication Dec 1, 2020; accepted for publication Dec 1, 2020; available ahead of print Jan 6, 2021.

Address for reprints: Faisal G. Bakaeen, MD, Department of Thoracic and Cardiovascular Surgery, Heart, Vascular and Thoracic Institute, 9500 Euclid Ave, Cleveland, OH 44195 (E-mail: bakaeef@ ccf.org).

JTCVS Techniques 2021;7:131-7

2666-2507

Copyright (C) 2021 The Authors. Published by Elsevier Inc. on behalf of The American Association for Thoracic Surgery. This is an open access article under the CC BY-NCND license (http://creativecommons.org/licenses/by-nc-nd/4.0/).

https://doi.org/10.1016/j.xjtc.2020.12.040
}

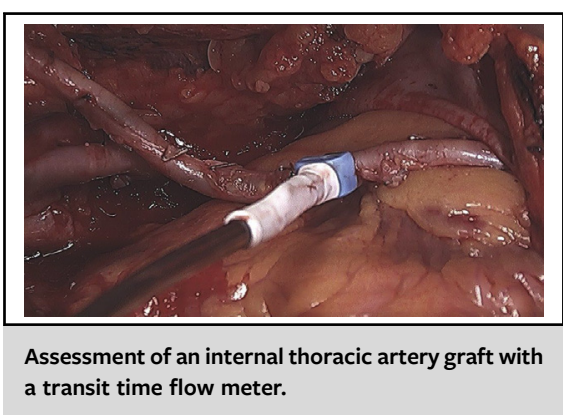

\begin{abstract}
CENTRAL MESSAGE
Graft flow assessment is a useful quality assurance adjunct but not a substitute for good technique and sound judgment. Judicious interpretation of flow readings ensures unnecessary graft revisions.
\end{abstract}

See Commentaries on pages $138,140,142$, and 144.

impractical and rarely performed, other flow and imaging modalities have made the stage, but their role and value in modern-day practice continues to evolve. Here, we review some of the available tools to assess intraoperative graft patency and evaluate their impact on the conduct and outcomes of CABG.

\section{INTRAOPERATIVE ASSESSMENT}

Several modalities that can aid in verifying conduit patency.

\section{Transit Time Flow Measurement (TTFM)}

TTFM (Figure 1) is based on the difference between the transit time of ultrasonic energy from 2 transducers in a probe passing through a liquid. ${ }^{8}$ Basic knowledge of TTFM is easy to grasp, with a quick learning curve.

Flow characteristics may vary depending on hemodynamics, postbypass myocardial recovery, spasm, or air in the graft. Several measurements should be taken before rushing into graft revisions, unless a cause is identified. TTFM cut-off values that were shown to influence patency are as follows ${ }^{8-11}$ :

1. Flow: acceptable $>20 \mathrm{~mL} / \mathrm{min}$. 


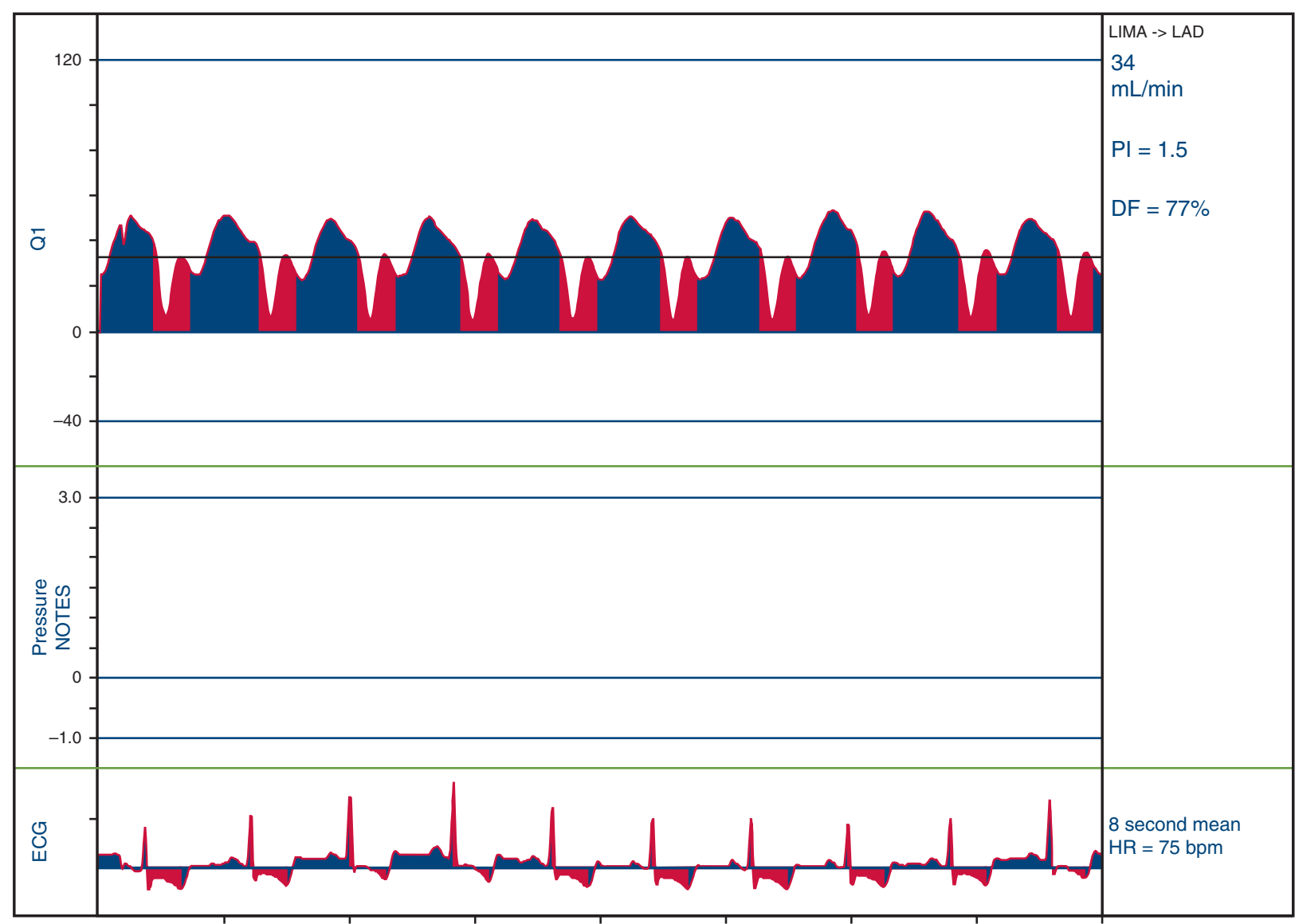

FIGURE 1. Transit time flow measurement. Flow measurement of LITA-LAD. Flow: $34 \mathrm{~mL} / \mathrm{min}$, PI: 1.5, DF: 77\%. LITA, Left internal thoracic artery; $L A D$, left anterior descending; PI, pulsatility index; $D I$, diastolic filling; $E C G$, electrocardiogram.

2. Pulsatility index (PI): measures resistance. It is the difference between the maximum and minimum flow divided by the mean flow. PI $=$ Qmax - Qmin/Qmean $(\mathrm{Q}=$ flow $)$. Ideally, $\mathrm{PI}$ is $<3$; acceptable $<5$.

3. Diastolic filling (DF) is defined as the percentage of coronary filling during diastole $(60 \%-70 \%$ for the left and $50 \%-60 \%$ for the right coronary).

4. Back flow or insufficiency ratio: flow back into the conduit. Typically, this should be less than $3 \%$ and is closely related to PI.

TTFM is measured at 4 intervals:

1. Once the distal anastomosis is completed and crossclamp still on. PI should be very low, with flatness of the curve due to nonpulsatile pump flow.

2. This is optional: same as stated previously, but with manual or snare proximal target occlusion (PTO), reducing retrograde flow into the coronary that may contribute to increased false negativity (TTFM good but bypass bad with distal obstruction).

3. Off-pump before administration of protamine. PTO may be performed if concerned about competitive flow.

4. Before chest closure.

\section{Epicardial Ultrasound (ECUS)}

ECUS is typically performed in conjunction with TTFM and best performed on a resting heart, providing an anatomical picture of the anastomosis and bypass graft. In one study, the false positivity of TTFM was dramatically lowered with the addition of ECUS, where only 2 of 39 grafts initially labeled as "failed" were reclassified as such. ${ }^{11}$ However, the majority of the false positivity was due to either retrograde or competitive flow, both can perhaps be excluded with PTO or "snare test."

\section{Intraoperative Indocyanine Green Imaging (ICG)}

ICG dye is excited with dispersed laser light creating an angiographic depiction of the graft, anastomosis, and native vessel. A randomized trial comparing TTFM with ICG found greater sensitivity and specificity with $\mathrm{ICG}^{12}$; however, it did not gain traction, perhaps due to its cumbersome use and need to obtain several views for complete graft visualization.

\section{Coronary Angiography}

Although it might be considered the gold standard, coronary angiography did not gain widespread adoption, due to 
the added time and needed personnel and hybrid operating rooms not commonly available. In a report by Hol and colleagues ${ }^{13}$ where post-CABG intraoperative angiography was carried out, a $4.2 \%$ immediate graft revision was undertaken ( $1.1 \%$ for on-pump vs $6.4 \%$ off-pump). An important finding was that two-thirds of the identified "lesions" were in the conduit itself rather than the anastomosis.

\section{OPERATIVE SCENARIOS}

\section{Technical Errors}

Compromised flow may result from suboptimal techniques in conduit harvesting, anastomosis suturing, or misjudging the length or lay of a graft. A dissection or hematoma of an arterial graft, or a displaced clip of a branch, may compromise luminal flow and go unnoticed. "Pursestringing" or "backwalling" during suture placement can narrow the inflow or outflow. A raised intimal flap or plaque disruption can be a threat to graft patency. While some problems such as a proximally located kink or twist in a graft are readily visible, other technical issues are perhaps less apparent and adjunct graft flow measurements or imaging modalities may add value.

\section{Competitive Native Flow}

The flow through a graft can be borderline or even poor due to competitive native flow (Figure 2), seen when the stenosis of the target vessel is not severe. Reduced graft patency has been documented when the radial artery is used for moderate stenosis, leading to a "string sign."14 Slightly reduced graft patency has been reported when the ITA is used to bypass a moderately diseased target. ${ }^{15} \mathrm{~A}$ correlation was documented between the degree of target vessel stenosis and the TTFMs of ITA grafts, where a "string sign" was noted in 50\% of nonstenotic lesions (fractional flow reserve $\geq 0.75$ ).${ }^{16}$ In another report, $75 \%$ of ITA grafts with competitive flow at initial angiography were found occluded at 5 years. ${ }^{17}$

Intraoperatively, marginal flow of an arterial graft bypassing a moderately diseased vessel can create a dilemma for an unsuspecting surgeon where the anastomosis "was just perfect," especially with no other electrocardiogram or transesophageal echocardiogram findings suggestive of ischemia.

Anticipation is key. We find it very helpful to measure flow after the completion of each bypass while on CPB with crossclamp on and perfusing the graft only. This is easily accomplished by removing the clamp off the ITA or perfusing the SVG with cardioplegia under a pressure of 80 to $120 \mathrm{~mm} \mathrm{Hg}$ and flow measured by the perfusionist. Establishing good flow characteristics without competitive native flow provides reassurance in case of marginal flow later once off $\mathrm{CPB}$ that might lure the surgeon into revising the graft unnecessarily. After separation from $\mathrm{CPB}$, or in off-pump coronary artery bypass (OPCAB) cases,

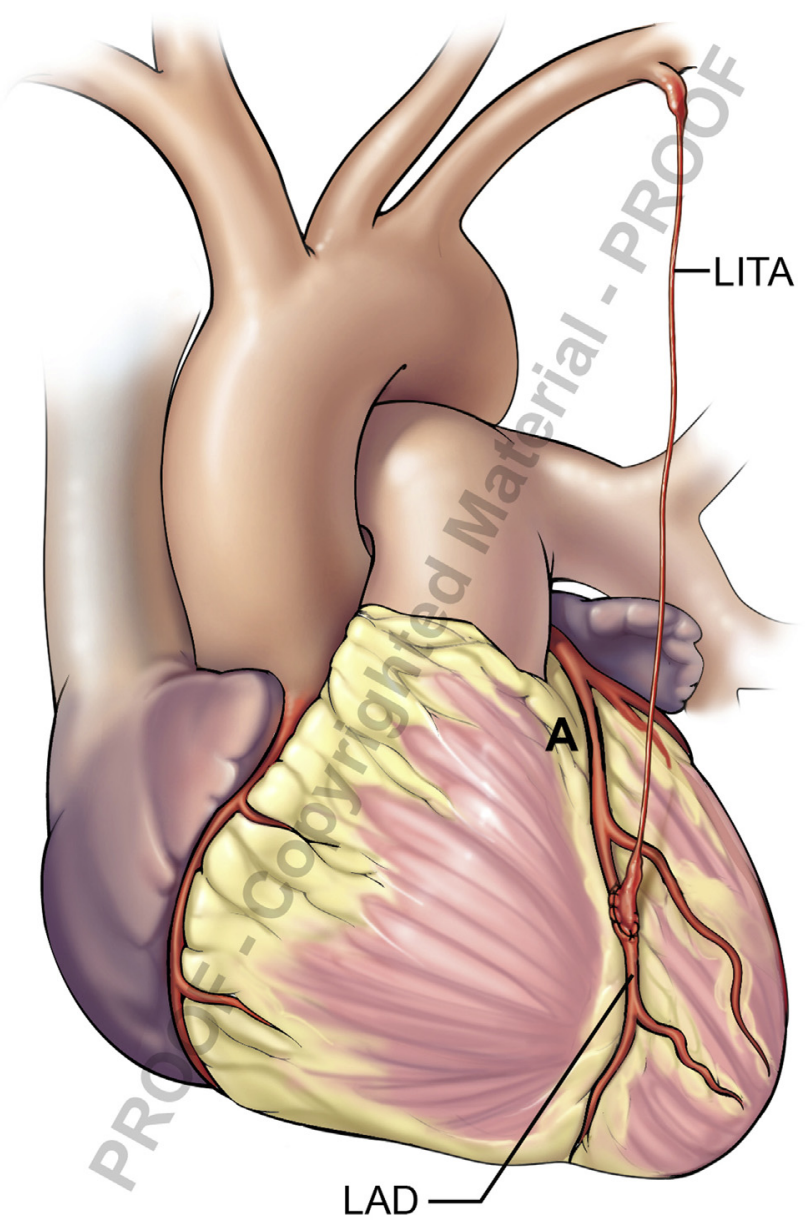

FIGURE 2. Competitive native flow. High native coronary flow due to mild LAD stenosis (A), resulting in LITA "string sign." LITA, Left internal thoracic artery; $L A D$, left anterior descending.

competitive native flow can be negated with PTO by manual or snare compression.

\section{Competitive Graft Flow}

Placing a vein graft in close proximity to an arterial graft with no significant disease between them may result in arterial "string sign" (Figure 3). An example would be left ITA-left anterior descending, with an SVG diagonal and no hemodynamically significant disease in-between. Left ITA flow may be poor but improves with occluding the vein graft. In such a situation, it would've been prudent not to graft the diagonal branch or to use the ITA sequentially or as composite grafts.

\section{Sequential Grafting}

Flow can be measured at different segments of the conduit to ensure their patency. A normal upstream flow reading does not exclude an occluded or compromised anastomosis if 1 or more other anastomoses in the sequence are patent. 


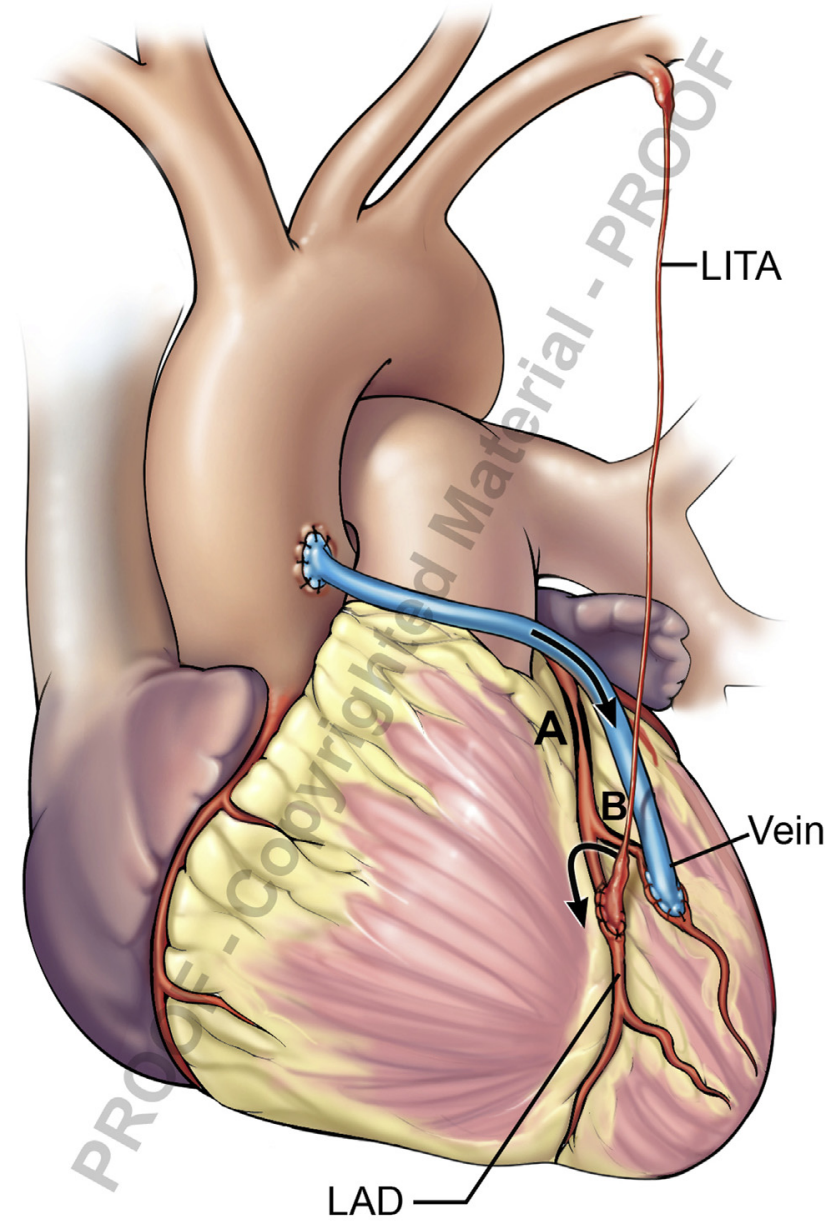

FIGURE 3. Competitive graft flow. High flow in neighboring veindiagonal, resulting in LITA "string sign.” A, Severe proximal LAD stenosis. B, Mild diagonal stenosis. LITA, Left internal thoracic artery; $L A D$, left anterior descending.

\section{Coronary-Coronary Steal Syndrome}

Coronary-coronary steal syndrome (Figure 4) occurs when one limb of an arterial composite graft is used to bypass a target that is not severely diseased. Back flow may be noted in the composite limb supplying that target. It is best not to construct a composite graft if one of the coronaries at hand is not severely stenotic. If already done, then the ITA limb supplying that non-left anterior descending target is transected and taken off as a free graft.

\section{Coronary-Subclavian Steal Syndrome}

Coronary-subclavian steal syndrome (Figure 5) occurs when the ITA is used with underlying severe proximal subclavian stenosis, resulting in reversal of flow into the ITA. Options include transecting the ITA at its origin and using it as a free graft or addressing the subclavian stenosis with a stent or carotid-subclavian bypass. Preoperative imaging can identify stenotic lesions preoperatively, and this is

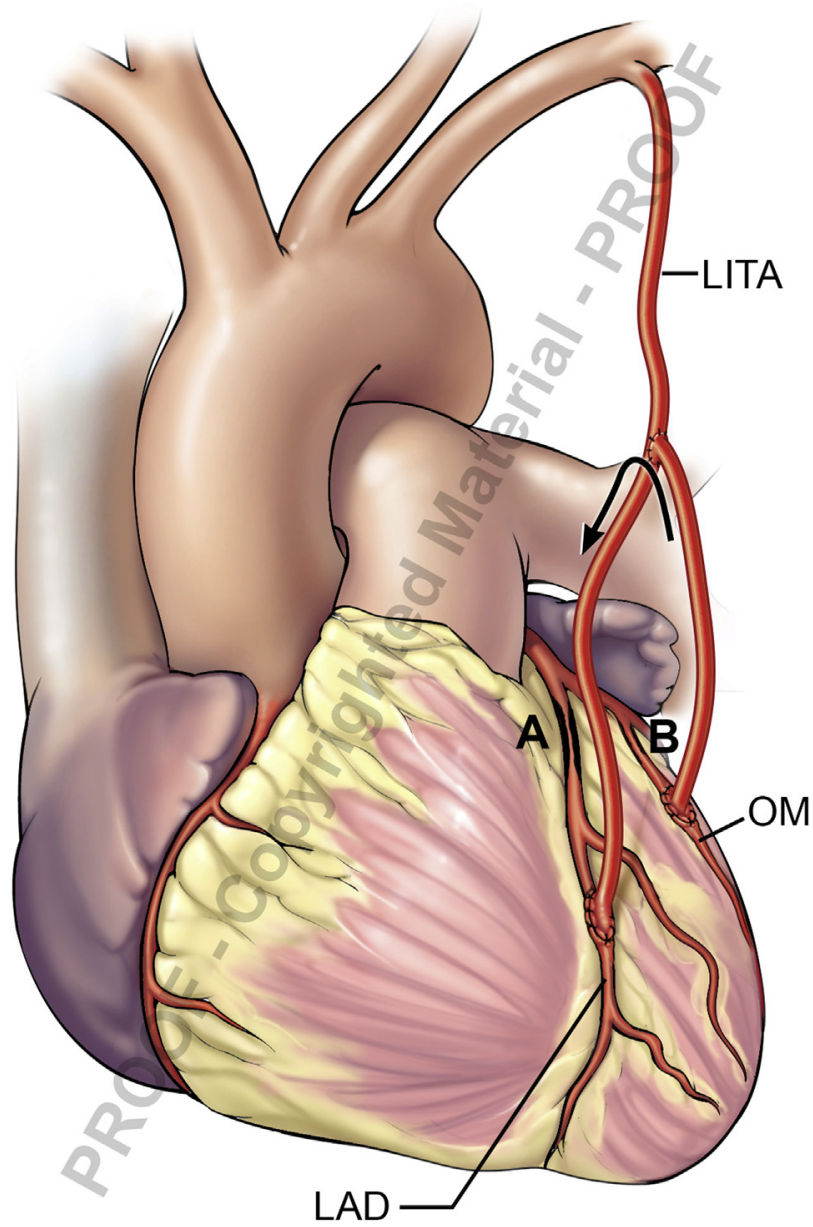

FIGURE 4. Coronary-coronary steal. High flow in native OM due to mild stenosis (B), resulting in retrograde flow up the composite BITA graft. A, Severe LAD stenosis. B, Mild OM stenosis. LITA, Left internal thoracic artery; $O M$, obtuse marginal; $L A D$, left anterior descending.

particularly important in patients with diffuse atherosclerotic disease especially when a no-touch aortic technique is contemplated because the entire inflow is based on 1 or 2 ITAs.

\section{Spasm}

Spasm can affect arterial conduits and coronary targets alike. It typically resolves with hemodynamic optimization or use of systemic or topical vasodilators. While significant tension at the distal anastomosis can distort or kink a coronary target, subtle tension can cause spasm. Likewise, air embolism can cause mechanical obstruction but can also induce spasm. The authors have found the administration of milrinone or nitroglycerine, systemically or directly injected into vein grafts with a fine caliber needle, to be effective in improving flow in scenarios where coronary spasm is suspected. 


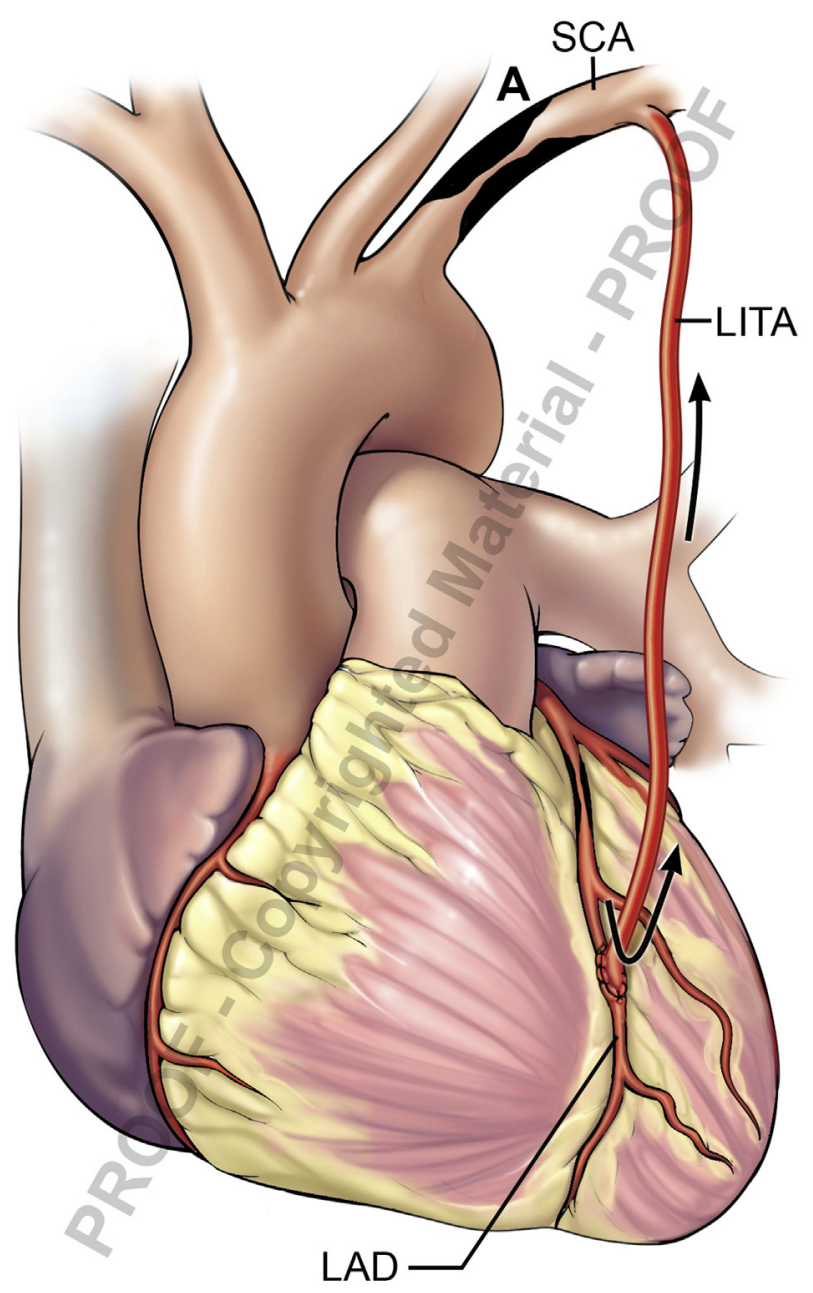

FIGURE 5. Coronary-subclavian steal. Severe proximal subclavian stenosis (A), resulting in LITA retrograde flow. A, Severe proximal SCA stenosis. SCA, Subclavian artery; LITA, Left internal thoracic artery; LAD, left anterior descending.

\section{DISCUSSION}

The earlier reports of surgeon-specific graft patency rates, mainly in $\mathrm{OPCAB}$, highlighted the importance of intraoperative graft assessment. ${ }^{18}$ The question is what data do we have to support the use of adjunct modalities for graft evaluation. Kim and colleagues ${ }^{19}$ reported angiographically proven better patency rates in arterial grafts in OPCAB after use of TTFM but not with vein grafts. Cut-off values for imperfect grafts included flow $<15 \mathrm{~mL} / \mathrm{min}$, PI $>3.0$, DF $\leq 50 \%$ for left-sided, and PI $>5.0$, DF $<50 \%$ for rightsided grafts. Interestingly, $50 \%$ of the revised grafts that continued with abnormal TTFM after revision were patent on early angiography. ${ }^{19}$

Di Giammarco and colleagues ${ }^{10}$ noted that intraoperative TTFM predicted early (12 months) arterial and vein grafts failures. A significant number of their cases were OPCAB and a lower-than-expected vein graft patency rate of $72 \%$ at 1 year was reported.

A review by Thuijs and colleagues ${ }^{9}$ noted that $4.3 \%$ of patients ( $2 \%$ of grafts) required graft revisions; however, of all grafts classified as abnormal only $25 \%$ were revised. The authors concluded that while TTFM could improve CABG procedures, due to the heterogeneous data, drawing uniform conclusions was challenging. In fact, in $50 \%$ of patients who had a "change" in their management, the decision was made without the need for TTFM. ${ }^{9}$

In a prospective study, Jokinen and colleagues correlated intraoperative TTFM with postoperative angiography. They found that cut-off values of flow $<15 \mathrm{~mL} / \mathrm{min}$ and PI $>3.0$ were indicative of imperfect grafts but were not consistently reliable, leading to unnecessary graft revisions. ${ }^{8,20}$

Several studies have shown no correlation between TTFM and clinical outcomes. ${ }^{21,22}$ However, Kieser and colleagues $^{23}$ reported a correlation between PI values and postoperative major adverse cardiac events but had a greater overall mortality of $4.8 \%$ than typically anticipated. ${ }^{23}$

The randomized Graft Imaging to Improve Patency (GRIIP) trial ${ }^{22}$ found no differences in graft failure at 1 year by coronary angiography between the control group and patients who underwent intraoperative TTFM. In addition, TTFM parameters did not correlate with 1-year graft failure. Indeed, $3.4 \%$ in the control group crossed over to the TTFM group based on the surgeon's suspicion and none of them met TTFM criteria for revision, yet more than one half were revised anyway. Moreover, 3.6\% in the TTFM group met criteria for revision and only one half were revised. At 1-year angiography, $75 \%$ of the nonrevised abnormal TTFM grafts were patent.

The Registry for Quality Assessment with Ultrasound Imaging and Transit-time Flow Measurement in Cardiac Bypass Surgery (REQUEST) was a multicenter, prospective, nonrandomized study. Graft revision occurred in $7.8 \%$, but with the nonrandomized nature of the study, it was unclear whether many of these changes were to happen anyway because of surgical judgment rather than predefined end point measures. The authors admitted that with the lack of post-CABG angiographic followup, no inference could be drawn whether routine graft assessment actually improves long-term graft patency or clinical outcomes. ${ }^{24}$

It has been suggested that the "Achilles heel" of TTFM is its false negativity, implying a bad graft but good TTFM due to retrograde flow into the coronary in face of a distal or an anastomotic toe obstruction. TTFM with PTO, manually or with snare, should turn the falsely negative test into a positive one, alleviating such confusion, as described by others. ${ }^{8}$ In our opinion, the true dilemma and "Achilles heel" is the false positivity (good graft, bad TTFM), misleading surgeons into revising grafts unnecessarily. 
Arterial conduits, especially the ITAs, are ideal conduits that are rarely affected by atherosclerosis and intimal hyperplasia that contribute to graft failure. However, ITAs are delicate and less-forgiving structures compared with veins, making them more prone to injuries. As such, if there were a graft to fail due to technical inadequacies, it should be the ITA and not the vein, yet venous graft predilection for even early failure underscores the importance of patientrelated risk factors, including coronary target quality and runoff in influencing conduit patency. ${ }^{22}$

Several factors may have hampered the widespread adoption of intraoperative quality verification of bypass grafts. For one, surgeons may feel confident that "they can figure things out" with visual inspection and other tools such as electrocardiography and transesophageal echocardiography that would alert them to issues relating to myocardial ischemia. Even proponents of intraoperative TTFM admit measurements can be "confusing" about $15 \%$ of the time, which may lead to unnecessary revisions, and only $25 \%$ of grafts with abnormal TTFM were actually revised. ${ }^{8,9}$

Is "perfect the enemy of good?" If "things are looking just fine," will "looking too hard" with additional tools become our foe? Indeed, reports noted that up to $73 \%$ of "lesions" identified at intraoperative or early postoperative angiography resolved spontaneously. Thrombus, wall hematoma, edema, and spasm all can mimic a true lesion. ${ }^{25}$ Misleading the surgeon into revising an otherwise-good anastomosis is a big deal, especially when handling a small, fragile, diffusely diseased vessel potentially compromising it. When ECUS was added to TTFM, the number of revisions fell to $0.7 \%$, in a way emphasizing the low need to revise grafts. ${ }^{8,11}$

Flow measurement and graft imaging modalities are not meant to substitute precise meticulous technique and surgical judgment. Even in centers that routinely use intraoperative assessment tools, the decision to revise a graft or not is heavily influenced by the surgeon's judgment rather than strict predetermined criteria. Graft patency in general is more related to patient's risk factors rather than technical mishaps. ${ }^{8,11,22}$ While fully recognizing that the potential of "avoidable" technical errors still exists, it perhaps accounts for a smaller percentage of graft failures than advertised.

Flow verification, especially of the arterial grafts, is particularly relevant with the increased complexity and nuances of MAG and the inability to "test inject" the ITA conduits similar to veins.

In summary (Video 1), we can distill our observations and recommendations to the following:

1. In general, flow meter use is helpful, and its routine use is recommended in MAG and off-pump CABG.

2. Selective use of the flow meter is recommended if there are any doubts about the integrity of the graft as a supple-

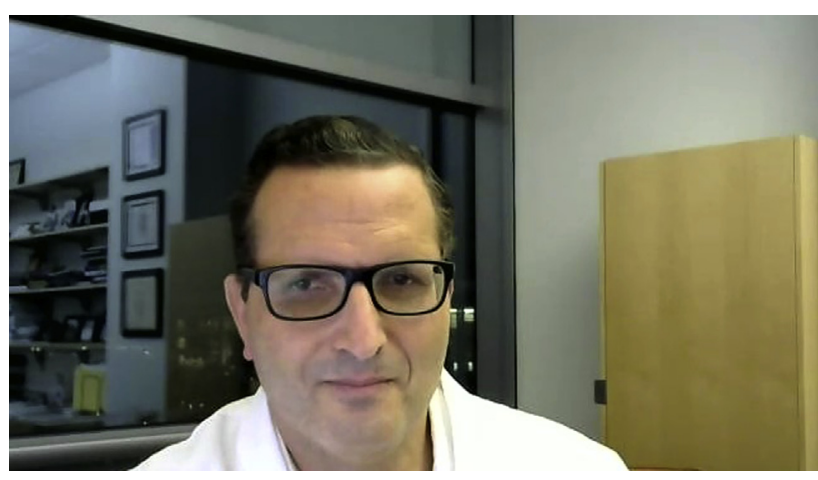

VIDEO 1. Dr Bakaeen summarizes the key points about intraoperative graft patency validation. Video available at: https://www.jtcvs.org/article/ S2666-2507(21)00026-2/fulltext.

ment to the surgeon's clinical judgment. For a meaningful assessment and interpretation, the surgeon should be familiar with flow measurement.

3. Flow measurements are best performed when the hemodynamics are optimized and, ideally, with no or minimal vasopressors on board to avoid spasm-related diminished flow.

4. Suboptimal flow measurements mandate a thorough investigation of a potential graft compromise but should not trigger an automatic graft revision.

5. Competitive flow, imbalanced flow, and arterial conduit/ coronary spasm are more frequent causes of poor flow measurements than technical issues.

6. Persistent zero or near-zero flow is usually associated with a real graft compromise.

7. The risk-benefit ratio and surgeon judgment are the 2 key components of the formula that determine how to react to a poor graft flow measurement.

In conclusion, intraoperative graft flow assessment together with increased use of MAG go hand in hand and are significant steps in the refinement of surgical revascularization toward the goal of improved short- and long-term outcomes. Surgeons should up their game with MAG, emphasizing quality assurance and durability.

\section{Conflict of Interest Statement}

The authors reported no conflicts of interest.

The Journal policy requires editors and reviewers to disclose conflicts of interest and to decline handling or reviewing manuscripts for which they may have a conflict of interest. The editors and reviewers of this article have no conflicts of interest.

The authors would like to thank Miss Deena Akras for her contribution in sketching the illustrations.

\section{References}

1. Balacumaraswami L, Taggart DP. Intraoperative imaging techniques to assess coronary artery bypass graft patency. Ann Thorac Surg. 2007;83:2251-7. 
2. Alexander JH, Hafley G, Harrington RA, Peterson ED, Ferguson TB, Lorenz TJ, et al. Efficacy and safety of edifoligide, an E2F transcription factor decoy, for prevention of vein graft failure following coronary artery bypass graft surgery: PREVENT IV: a randomized controlled trial. J Am Med Assoc. 2005;294:2446-54.

3. Aldea GS, Bakaeen FG, Pal J, Fremes S, Head SJ, Sabik J, et al. The Society of Thoracic Surgeons clinical practice guidelines on arterial conduits for coronary artery bypass grafting. Ann Thorac Surg. 2016;101:801-9.

4. Loop FD, Lytle BW, Cosgrove DM, Stewart RW, Goormastic M, Williams GW, Influence of the internal-mammary-artery graft on 10-year survival and other cardiac events. N Engl J Med. 1986;314:1-6.

5. Lytle BW, Blackstone EH, Loop FD, Houghtaling PL, Arnold JH, Akhrass R, et al. Two internal thoracic artery grafts are better than one. J Thorac Cardiovasc Surg. 1999;117:855-72.

6. Rocha RV, Tam DY, Karkhanis R, Nedadur R, Fang J, Tu JV, et al. Multiple arterial grafting is associated with better outcomes for coronary artery bypass grafting patients. Circulation. 2018;138:2081-90.

7. Bakaeen FG, Ravichandren K, Blackstone EH, Houghtaling PL, Soltesz EG, Johnston DR, et al. Coronary artery target selection and survival after bilateral internal thoracic artery grafting. J Am Coll Cardiol. 2020;75:258-68.

8. Kieser TM. Graft quality verification in coronary artery bypass graft surgery: how, when and why? Curr Opin Cardiol. 2017;32:722-36.

9. Thuijs DJFM, Bekker MWA, Taggart DP, Pieter Kappetein A, Kieser TM, Wendt $\mathrm{D}$, et al. Improving coronary artery bypass grafting: a systematic review and meta-analysis on the impact of adopting transit-time flow measurement. Eur J Cardiothorac Surg. 2019;56:654-63.

10. Di Giammarco G, Pano M, Cirmeni S, Pelini P, Vitolla G, Di Mauro M. Predictive value of intraoperative transit-time flow measurement for short-term graft patency in coronary surgery. J Thorac Cardiovasc Surg. 2006;132:468-74.

11. Di Giammarco G, Canosa C, Foschi M, Rabozzi R, Marinelli D, Masuyama S, et al. Intraoperative graft verification in coronary surgery: increased diagnostic accuracy adding high-resolution epicardial ultrasonography to transit-time flow measurement. Eur J Cardiothorac Surg. 2014;45:41-5.

12. Desai ND, Miwa S, Kodama D, Koyama T, Cohen G, Pelletier MP, et al. A randomized comparison of intraoperative indocyanine green angiography and transit-time flow measurement to detect technical errors in coronary bypass grafts. J Thorac Cardiovasc Surg. 2006;132:585-94.

13. Desai ND, Miwa S, Kodama D, Koyama T, Cohen G, Pelletier MP, et al. Intraoperative angiography leads to graft revision in coronary artery bypass surgery. Ann Thorac Surg. 2004;78:502-5.

14. Cao C, Manganas C, Horton M, Bannon P, Munkholm-Larsen S, Ang SC, et al. Angiographic outcomes of radial artery versus saphenous vein in coronary artery bypass graft surgery: a meta-analysis of randomized controlled trials. J Thorac Cardiovasc Surg. 2013;146:255-61.
15. Raza S, Blackstone EH, Houghtaling PL, Olivares G, Ravichandren K, Koprivanac M, et al. Natural history of moderate coronary artery stenosis after surgical revascularization. Ann Thorac Surg. 2018;105:815-21.

16. Honda K, Okamura Y, Nishimura Y, Uchita S, Yuzaki M, Kaneko M, et al. Graft flow assessment using a transit time flow meter in fractional flow reserve-guided coronary artery bypass surgery. J Thorac Cardiovasc Surg. 2015;149:1622-8.

17. Nakajima H, Kobayashi J, Tagusari O, Niwaya K, Funatsu T, Kawamura A, et al Angiographic flow grading and graft arrangement of arterial conduits. J Thorac Cardiovasc Surg. 2006;132:1023-9.

18. Puskas JD, Williams WH, Mahoney EM, Huber PR, Block PC, Duke PG, et al Off-pump vs conventional coronary artery bypass grafting: early and 1-year graft patency, cost, and quality-of-life outcomes: a randomized trial. J Am Med Assoc. 2004;291:1841-9.

19. Kim KB, Kim JS, Kang HJ, Koo BK, Kim HS, Oh BH, et al. Ten-year experience with off-pump coronary artery bypass grafting: lessons learned from early postoperative angiography. J Thorac Cardiovasc Surg. 2010;139: 256-62.

20. Jokinen JJ, Werkkala K, Vainikka T, Peräkylä T, Simpanen J, Ihlberg L. Clinical value of intra-operative transit-time flow measurement for coronary artery bypass grafting: a prospective angiography-controlled study. Eur J Cardiothorac Surg. 2011;39:918-23.

21. De Leon M, Stanham R, Soca G, Dayan V. Do flow and pulsatility index within the accepted ranges predict long-term outcomes after coronary artery bypass grafting? Thorac Cardiovasc Surg. 2020;68:162-8.

22. Singh SK, Desai ND, Chikazawa G, Tsuneyoshi H, Vincent J, Zagorski BM, et al The graft imaging to improve patency (GRIIP) clinical trial results. J Thorac Cardiovasc Surg. 2010;139:294-301.e1.

23. Kieser TM, Rose S, Kowalewski R, Belenkie I. Transit-time flow predicts outcomes in coronary artery bypass graft patients: a series of 1000 consecutive arterial grafts. Eur J Cardiothorac Surg. 2010;38:155-62.

24. Taggart DP, Thuijs DJFM, Di Giammarco G, Puskas JD, Wendt D, Trachiotis GD, et al. Intraoperative transit-time flow measurement and highfrequency ultrasound assessment in coronary artery bypass grafting. $J$ Thorac Cardiovasc Surg. 2020;159:1283-92.e2.

25. Hol PK, Fosse E, Lundblad R, Nitter-Hauge S, Due-Tønnessen P, Vatne K, et al. The importance of intraoperative angiographic findings for predicting long-term patency in coronary artery bypass operations. Ann Thorac Surg. 2002;73:813-8.

Key Words: flow meter, competitive flow, graft patency, coronary artery bypass grafting, transit time flow meter 